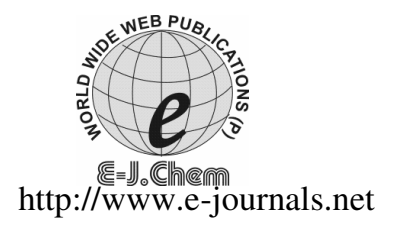

ISSN: 0973-4945; CODEN ECJHAO

E-Journal of Chemistry

$2011,8(2), 621-628$

\title{
Adsorption and Corrosion Inhibition Effect of $N$-(l-Morpholinobenzyl)urea on Mild Steel in Acidic Medium
}

\author{
M. ANWAR SATHIQ ${ }^{\S *}$, A. JAMAL ABDUL NASSER ${ }^{\S}$ and \\ P. MOHAMED SIRAJUDEEN
}

${ }^{\S} \mathrm{PG}$ and Research Department of Chemistry, Jamal Mohamed College

(Autonomous) Tiruchirappalli - 620020, Tamilnadu, India

PG and Research Department of Chemistry, Khadir Mohideen College

Adirampattinum- 614701, Tamilnadu, India

anwarchemsathiq@yahoo.co.in

Received 20 September 2010; Revised 27 October 2010; Accepted 29 October 2010

\begin{abstract}
The influence of $N$-(l-morpholinobenzyl)urea (MBU) on corrosion inhibition of mild steel in $1 \mathrm{M} \mathrm{HCl}$ was studied by weight loss, effect of temperature, potentiodynamic polarization and electrochemical impedance spectroscopy. The experimental results showed that the inhibition efficiency increases with increasing of MBU concentrations but decreases with increasing temperatures. The adsorption of MBU on the mild steel surface obeyed the Temkin's adsorption isotherm. Potentiodynamic polarization curves showed that MBU acted as a cathodic inhibitor predominantly in hydrochloric acid. This was supported by the impedance measurements which showed a change in the charge transfer resistance and double layer capacitance indicating adsorption of $\mathrm{MBU}$ on the mild steel surface. Protective film formation against the acid attack is confirmed by SEM.
\end{abstract}

Keywords: $N$-(1-Morpholinobenzyl)urea, Mildsteel, Temkin's adsorption isotherm, Potentiodynamic polarization, Corrosion inhibitor

\section{Introduction}

Hydrochloric acid is widely used in the pickling, cleaning and descaling of steel and ferrous alloys. Acid solutions are generally used for the removal of rust and scale in industrial processes. Inhibitors are often used in these processes to control the metal dissolution ${ }^{1-3}$. Most of the well known acid inhibitors are organic compounds containing nitrogen, sulphur and oxygen atoms ${ }^{4-6}$. Recently sulphur and nitrogen containing heterocyclic compounds with various substituents are considered to be very effective corrosion inhibitors ${ }^{7-15}$.

The role of inhibitors is to form a barrier of one or several molecular layers against the acid attack. In general, protective action is often associated with chemical or physical 
adsorption involving a variation in charge of adsorbed substance and transfer of charge from one phase to another phase ${ }^{3}$. In the present work, the corrosion inhibiting behavior of MBU was investigated on mild steel in $\mathrm{HCl}$ solutions by various methods.

\section{Experimental}

Mild steel strips with the composition Carbon $=0.07 \%$; Sulphur $=$ Nil; Phosphorus $=0.008 \%$; Silicon $=$ Nil; Manganese $=0.34 \%$ and Iron $=$ reminder and size of $4 \times 1 \times 0.025 \mathrm{~cm}$ were used for weight loss and effect of temperature studies. Mild steel cylindrical rods of the same composition embedded in araldite with exposed area of $1 \mathrm{~cm}^{2}$ were used for potentiodynamic polarization and impedance measurements. The electrode was polished using a sequence of emery papers of different grades and then degreased with acetone. $N-\left(1-\right.$ morpholinobenzyl)urea was synthesized ${ }^{16}$, and purified by recrystalization from ethanol to analytical purity grade. Its purity was confirmed by elemental analysis and characterized by IR and NMR spectroscopy. The acid solution $(1 \mathrm{M} \mathrm{HCl})$ was prepared by dilution of analytical grade $37 \% \mathrm{HCl}$ with double distilled water. All tests were conducted at different temperatures in magnetically stirred solutions.

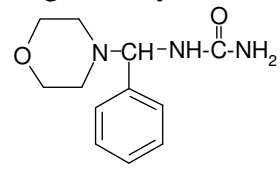

Figure 1. Molecular structure of $\mathrm{N}$-(1-morpholinobenzyl)urea

Weight loss measurements were carried out as described earlier ${ }^{13}$. Triplicate mild steel specimens weighed already were suspended in $100 \mathrm{~mL}$ of inhibited and uninhibited solutions kept in a $100 \mathrm{~mL}$ beaker for $2 \mathrm{~h}$. At the end of the period, specimens were taken out, washed well with running water, dried thoroughly and finally weighed. Inhibition efficiency was calculated from the weight losses of specimens in the absence and presence of the inhibitor. The loss in weights was calculated at different temperatures from 308 to $333 \mathrm{~K}$. Each experiment was duplicated to get good reproducibility. Weight loss measurements were performed in $1 \mathrm{M} \mathrm{HCl}$ with and without the addition of the inhibitor at their best inhibiting concentrations. Percentage inhibitions of the inhibitor at various temperatures were calculated. Both cathodic and anodic polarization curves were recorded $(1 \mathrm{mv} / \mathrm{S})$ using the corrosion measurement system BAS (Model: $100 \mathrm{~A}$ ) computerized electrochemical analyzer and PL-10 digital Plotter. A platinum foil and $\mathrm{Hg}\left|\mathrm{Hg}_{2} \mathrm{Cl}_{2}\right| 1 \mathrm{M} \mathrm{HCl}$ electrode were used as auxiliary and reference electrodes respectively. Electrochemical measurements were carried out in the conventional three-electrode, cylindrical pyrex glass cell with a capacity of $1000 \mathrm{~mL}$. The working electrode in the form of disc cut from mild steel with geometric area of $1 \mathrm{~cm}^{2}$ was embedded in polytetrafluoroethylene (PTFE). A saturated calomel electrode (SCE) and a platinum disc electrode were used, respectively, as reference and auxiliary electrodes. The temperature was controlled at $303 \mathrm{~K}$ by thermostat. The working electrode was abraded with silicon carbide paper (grade P1200), degreased with AR grade ethanol and acetone and rinsed with double distilled water before use. All potentials are reported versus SCE. The adsorption free energy changes in all the various concentrations of MBU at ordinary temperature $(303 \mathrm{~K} \pm 1)$ and $10^{-2} \mathrm{M}$ concentration (best inhibition) of MBU at different temperatures ( 313 to $333 \mathrm{~K}$ ) were calculated ${ }^{15}$ using the equation $\Delta \mathrm{G}^{0}=-\mathrm{RT} \ln (\mathrm{K} 55.5$ ) $\mathrm{kJ} /$ mole, Where $\Delta \mathrm{G}^{0}=$ adsorption free energy, $\mathrm{R}=$ Gas Constant in $\mathrm{kJ}, \mathrm{T}=$ Temperature in $\mathrm{K}$, $\mathrm{K}=$ Adsorptive equilibrium constant in $\mathrm{L} \mathrm{mol}^{-1 .}$ The value of 55.5 is the concentration of water in solution expressed in mol $L^{-1}$. The value of $K$ was calculated from $K=\theta / C(1-\theta)$. where $\theta=$ surface coverage (Inhibition efficiency/100) and $\mathrm{C}=$ inhibitor concentration. The specimens used for surface morphological examination were immersed in acid containing various 
concentrations of inhibitor and blank for $2 \mathrm{~h}$. Then they were removed, rinsed quickly with rectified spirit and dried. The analysis was performed on HITACHI-model S-3000 H SEM.

\section{Results and Discussion}

\section{Weight loss measurements}

Table 1 gives the values of inhibition efficiency for different concentrations of MBU in $1 \mathrm{M}$ $\mathrm{HCl}$. It can be seen from this table that MBU efficiently inhibits the corrosion of mild steel in $1 \mathrm{M} \mathrm{HCl}$ solutions. This is due to the presence of hetero atoms like nitrogen and oxygen. The adsorption is assumed to be a quasi-substitution process between the water molecules on the surface and the organic molecules. MBU is adsorbed vertically with $-\mathrm{NH}$ group as the anchoring group ${ }^{14}$. The interaction of MBU with the metal surface may occur through both the - $\mathrm{NH}$ and the - $\mathrm{CO}$ group. It is well known that in MBU, the lone pair of electrons of nitrogen is responsible for much predominant adsorption on the mild steel surface.

The greater inhibitive power of MBU may be due to the presence of three nitrogen, two oxygen atoms and an aromatic ring. Weight loss measurements revealed that corrosion inhibition efficiency of the MBU increases with increasing the concentration.

Table 1. Values of inhibition efficiencies for different concentrations of MBU in $1 \mathrm{M} \mathrm{HCl}$ at ordinary temperature

\begin{tabular}{cccc}
\hline $\begin{array}{c}\text { Concentration of } \\
\text { Inhibitor, M }\end{array}$ & Weight loss, g & $\begin{array}{c}\text { Corrosion } \\
\text { Rate, mpy }\end{array}$ & $\begin{array}{c}\text { Inhibition } \\
\text { Efficiency, \% }\end{array}$ \\
\hline Blank & 0.098 & 0.8676 & - \\
$10^{-7}$ & 0.046 & 0.4072 & 53.06 \\
$10^{-6}$ & 0.032 & 0.2833 & 67.35 \\
$10^{-5}$ & 0.023 & 0.2036 & 76.53 \\
$10^{-4}$ & 0.017 & 0.1505 & 82.65 \\
$10^{-3}$ & 0.011 & 0.0974 & 88.78 \\
$10^{-2}$ & 0.005 & 0.0443 & 94.89 \\
\hline
\end{tabular}

\section{Effect of temperature}

The effect of temperature on the performance of the MBU (Table 2) clearly indicates that the corrosion rate increases with increasing temperature. Adsorption and desorption of inhibitor molecules continuously occur at the metal surface and an equilibrium exists between two processes at a particular temperature. With increase of temperature, the equilibrium between the adsorption and desorption processes is shifted to a higher desorption rate than adsorption until equilibrium is again established at a different value of equilibrium constant. It explains the lower inhibition efficiency at higher temperature.

Table 2. Values of inhibition efficiencies and surface coverage for different temperatures in the presence of $10^{-2} \mathrm{M}$ concentration of $\mathrm{MBU}$ in $1 \mathrm{M} \mathrm{HCl}$

\begin{tabular}{ccccc}
\hline $\begin{array}{c}\text { Temperature, } \\
\text { K }\end{array}$ & $\theta$ & $1-\theta$ & $\begin{array}{c}\log \\
(\theta / 1-\theta)\end{array}$ & $\begin{array}{c}\text { Inhibition } \\
\text { Efficiency, } \%\end{array}$ \\
\hline 313 & 0.9388 & 0.0162 & 1.1858 & 93.88 \\
318 & 0.9272 & 0.0728 & 1.1050 & 92.72 \\
323 & 0.8639 & 0.1361 & 0.8026 & 86.39 \\
328 & 0.7957 & 0.2043 & 0.5904 & 79.57 \\
333 & 0.7555 & 0.2445 & 0.4899 & 75.55 \\
\hline
\end{tabular}


The arrhenius plots for the effect of temperature on the performance of the MBU at the optimum inhibition concentration of $0.01 \mathrm{M}$ are shown in Figure 2.

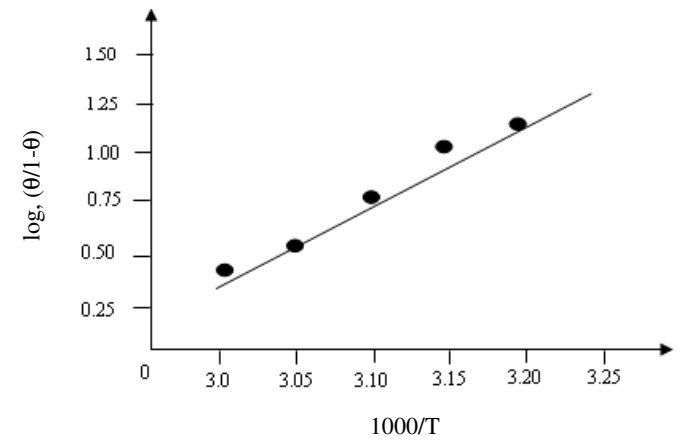

Figure 2. Arrhenius plots for mild steel in $1 \mathrm{M} \mathrm{HCl}$ in the presence of $10^{-2} \mathrm{M}$ concentration of MBU at different temperatures

\section{Potentiodynamic polarization studies}

It can be seen from the Table 3 that the values of $b_{c}$ (Tafel Cathodic control parameter) were shifted to higher values with reference to blank in the presence of MBU. This shows that the MBU inhibits the corrosion mechanism by controlling cathodic reactions predominantly and blocking cathodic sides of the metal surface. The $\mathrm{I}_{\text {corr }}$ (corrosion potential) value decreases with increasing the inhibitor concentration. The potentiodynamic polarization curves for mild steel in $1 \mathrm{M} \mathrm{HCl}$ in the presence of different concentrations of the MBU is shown in Figure 4.

Table 3. Corrosion kinetic parameters for the corrosion of mild steel in $1 \mathrm{M} \mathrm{HCl}$ containing different concentrations of the MBU.

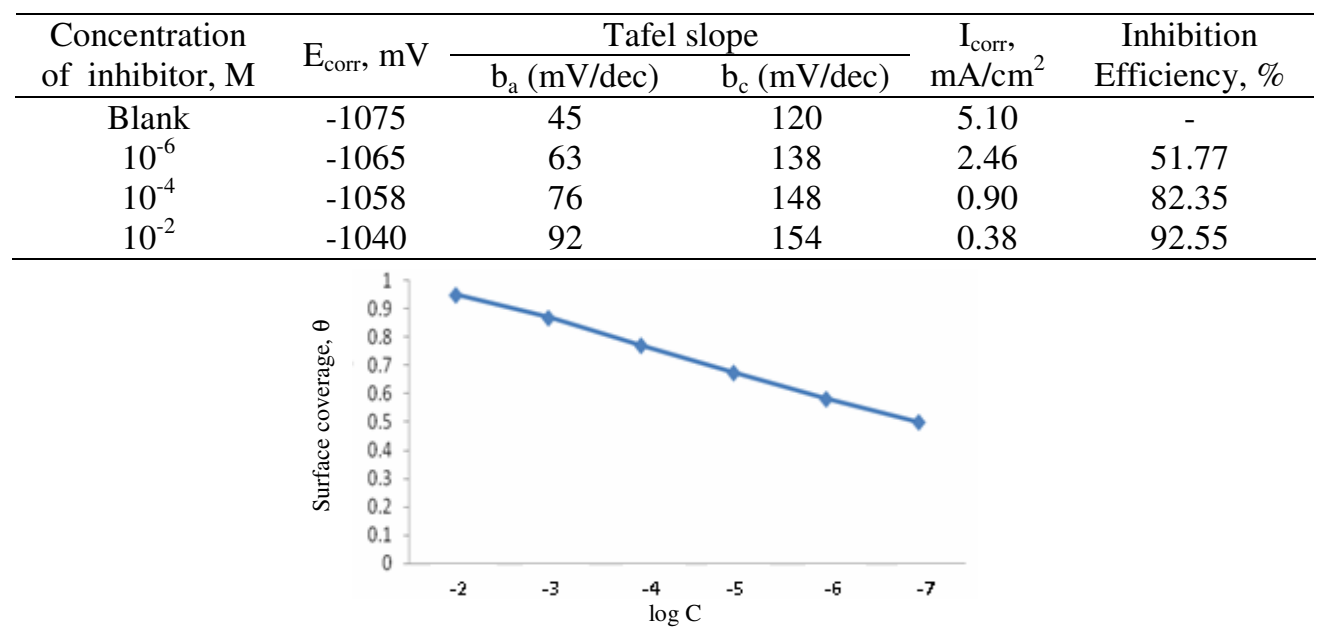

Figure 3. Temkin's adsorption isotherm plot for mild steel in $1 \mathrm{M} \mathrm{HCl}$ in the presence of MBU at different concentrations

\section{Electrochemical impedance measurements}

Table 4 gives the values of $\mathrm{R}_{\mathrm{t}}, \mathrm{C}_{\mathrm{dl}}$ and $\mathrm{I}_{\text {corr }}$ which were derived from Nyquist plots shown in Figure 5. It can be seen from this Table that the charge transfer resistance $\left(R_{t}\right)$ value increases 
with increasing $\mathrm{MBU}$ concentration but the double layer capacitance $\left(\mathrm{C}_{\mathrm{dl}}\right)$ value decreases due to the decrease in local dielectric constant and increase in the thickness of the electrical double layer. Both electrochemical impedance and potentiodynamic polarization results are in very good agreement with weight loss measurements.

Table 4. Impedance parameters for the corrosion of mild steel in $1 \mathrm{M} \mathrm{HCl}$ containing different concentrations of the MBU.

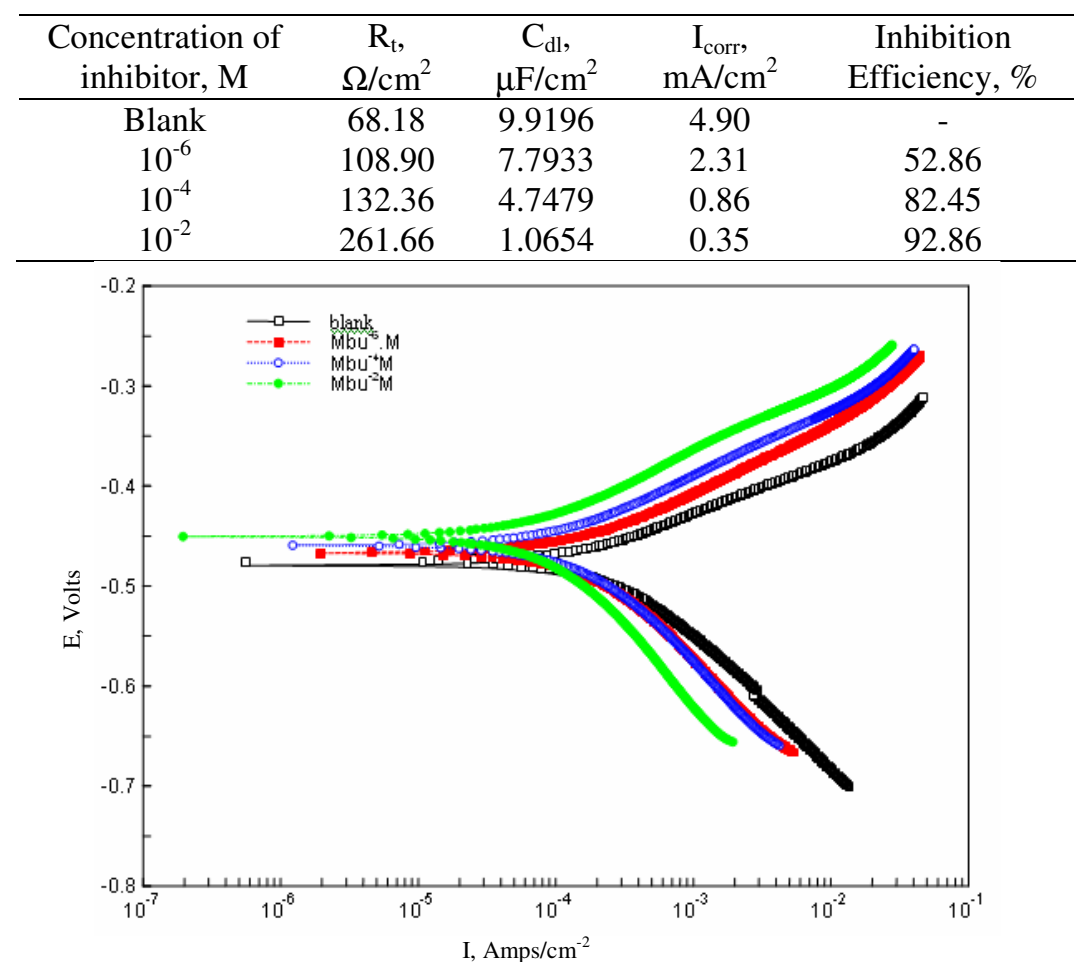

Figure 4. Potentiodynamic polarization curves for mild steel in $1 \mathrm{M} \mathrm{HCl}$ in the presence of different concentrations of the MBU.

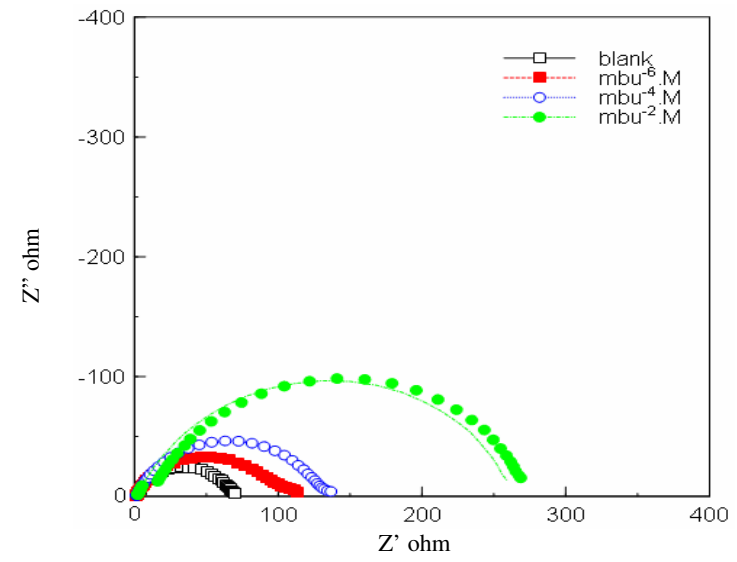

Figure 5. Nyquist plots for mild steel in $1 \mathrm{M} \mathrm{HCl}$ in the presence of different concentrations of the MBU. 


\section{Adsorption free energy change}

Table 5 and 6 give the values of free energy of adsorption change for all the various concentrations of MBU at ordinary temperature and different temperatures of optimum concentrations respectively.

Table 5. Values of free energy changes for the corrosion of mild steel in $1 \mathrm{M} \mathrm{HCl}$ in the presence of different concentrations of $\mathrm{MBU}$ at ordinary temperature

\begin{tabular}{ccccc}
\hline $\begin{array}{c}\text { Concentration, } \\
\mathrm{M}\end{array}$ & $\theta$ & $1-\theta$ & $\begin{array}{c}\text { Log, } \\
\theta / 1-\theta\end{array}$ & $\begin{array}{c}\Delta \mathrm{G}, \\
\mathrm{kJ} / \mathrm{mole}\end{array}$ \\
\hline $10^{-7}$ & 0.5306 & 0.4694 & 0.1226 & -66.97 \\
$10^{-6}$ & 0.6735 & 0.3265 & 0.7241 & -75.38 \\
$10^{-5}$ & 0.7653 & 0.2347 & 1.1819 & -85.79 \\
$10^{-4}$ & 0.8265 & 0.1735 & 1.5610 & -96.95 \\
$10^{-3}$ & 0.8878 & 0.1122 & 2.068 & -107.66 \\
$10^{-2}$ & 0.9489 & 0.0511 & 2.9215 & -117.64 \\
\hline
\end{tabular}

It has been observed in Table 5 that as the concentration of the MBU increases, the free energy of adsorption also increases. This shows that the adsorption process becomes easier with increase in the concentration of inhibitor. In Table 6, as the temperature increases the free energy of adsorption decreases. This shows that the corrosion process becomes easier with increasing temperature.

Table 6. Values of free energy changes for the corrosion of mild steel in $1 \mathrm{M} \mathrm{HCl}$ in the presence of $10^{-2} \mathrm{M}$ concentrations of MBU at different temperatures

\begin{tabular}{ccccc}
\hline $\begin{array}{c}\text { Temperature, } \\
\mathrm{K}\end{array}$ & $\theta$ & $1-\theta$ & $\begin{array}{c}\text { log, } \\
\theta / 1-\theta\end{array}$ & $\begin{array}{c}\Delta \mathrm{G}, \\
\mathrm{kJ} / \mathrm{mole}\end{array}$ \\
\hline 313 & 0.9388 & 0.0612 & 1.1858 & -68.03 \\
318 & 0.9272 & 0.0728 & 1.1050 & -67.98 \\
323 & 0.8639 & 0.1361 & 0.8026 & -64.75 \\
328 & 0.7957 & 0.2043 & 0.5904 & -62.68 \\
333 & 0.7555 & 0.2445 & 0.4899 & -62.16 \\
\hline
\end{tabular}

Temkin's adsorption isotherm

Adsorbed organic molecules may interact each other or with the metal surface. The latter may be by chemisorptions. The degree of surface coverage $(\theta)$ for different concentration of $\mathrm{MBU}$ in $1 \mathrm{M} \mathrm{HCl}$ was evaluated ${ }^{13}$. These surface coverage values were tested graphically by fitting to a suitable adsorption isotherm. Figure 3 shows that adsorption in this system can be fitted by a Temkin's adsorption isotherm.

\section{SEM analysis}

SEM photograph of the metal sample in the presence and absence of inhibitor are shown in Figure 6 and 7. The inhibited metal surface is smoother than the uninhibited surface indicating a protective layer of adsorbed inhibitor preventing acid attack. 


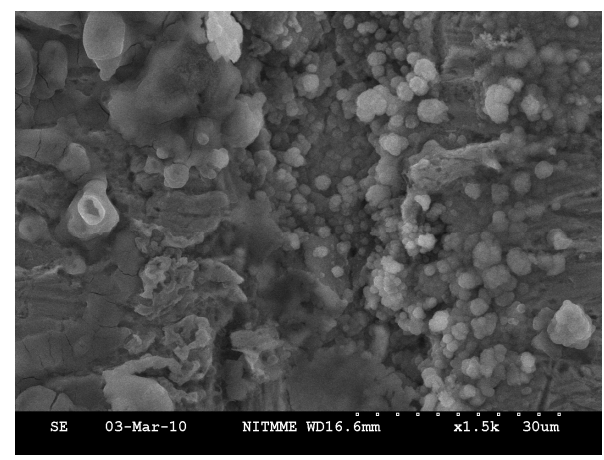

Figure 6. SEM image of surface of mild steel after immersion for $2 \mathrm{~h}$ in $1 \mathrm{M} \mathrm{HCl}$

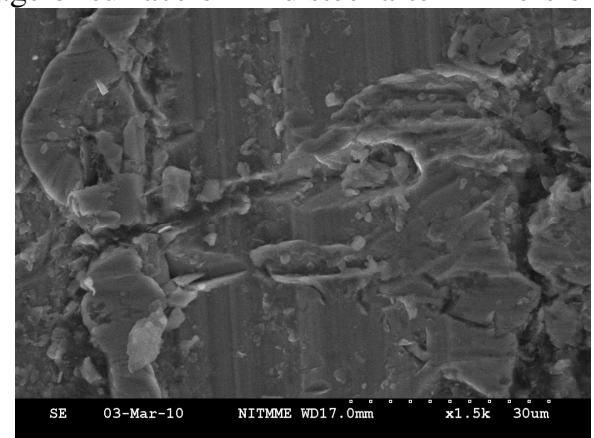

Figure 7. SEM image of surface of mild steel after immersion for $2 \mathrm{~h}$ in $1 \mathrm{M} \mathrm{HCl}$ in presence of $0.01 \mathrm{M} \mathrm{MBU}$

\section{Conclusion}

The main conclusions drawn from this study are MBU efficiently inhibits the corrosion of mild steel in $1 \mathrm{M} \mathrm{HCl}$ medium. MBU behaves as predominantly cathodic control. Adsorption of MBU on the surface of mild steel from $1 \mathrm{M} \mathrm{HCl}$ obeys Temkin's adsorption isotherm. Reduction in the values of $\mathrm{I}_{\text {corr }}$ and $\mathrm{C}_{\mathrm{dl}}$ in the presence of an inhibitor has been dealt. The inhibition efficiency of MBU increases with increasing the inhibitor concentration. On increasing the temperature, the corrosion rate increases. Protective film formation against the acid attack is confirmed by SEM.

\section{Acknowledgment}

The authors thank the Director of ICP centre, CECRI, Karaikudi, for kind permission for providing the facilities of electrochemical studies and Prof. Dr. Muthupandi, MME, NIT, Trichy, for providing the SEM facilities and Principal, Jamal Mohamed College (Autonomous), Trichy - 20 for providing necessary facilities and encouragement.

\section{References}

1. Popova A Sokolova E Raicheva S and Christov M, Corros Sci., 2003, 33, 45.

2. Noor E A, Corros Sci., 2005, 47, 33-35.

3. Bouklah M, Hammoutim B, Benkaddour M and Benhadda T, J Appl Electrochem., 2005, 35, 1095-1101.

4. Ajmal M, Mideen A S and Quraishi M A, Corros Sci., 1994, 36, 78. 
5. Quraishi M A, Khan M A W, Ajmal M, Muralidharan S and Iyer S V, Anticorros Meth Mater, 1996, 43, 5.

6. $\quad$ Nasser A J A, Bull Electrochem., 2005, 21, 305-311.

7. Granese S L, Rosales B M, Oviedo C and Zerbino J O, Corros Sci., 1992, 33, 1439.

8. Quraishi M A and Sardar R, J Appl Electrochem., 2003, 33, 1163.

9. Muralidharan S Chandrasekar R and Iyer S V K, Proc Indian Acad Sci (Chem Sci)., 2000, 112(2), 127-136.

10. Khaled K F, Babic - Samarazija K and Hackerman N, Anticorros Meth Mater., 2004, 52, 11.

11. Bentiss F, Traisnel M and Lagrenee M, J Appl Electrochem., 2001, 31, 41.

12. Ahamed I, Prasad R and Quraishi, M A, Corros Sci., 2010, 52, 1472.

13. Muralidharan S Quraishi M A and Venkatakrishna Iyer S, Corros Sci., 1995, 37, 1739.

14. Jamal Abdul Nasser A and Anwar Sathiq M, Bull Electrochem., 2007, 23, 237-245.

15. Chaudhary R S Tyagi D K and Atul Kumar, J Sci Ind Res., 2007, 66(10), 835-840.

16. Venkatesa Prabu G and Mohamed Kasim A N, Asian J Chem, 2000, 12(2), 385. 


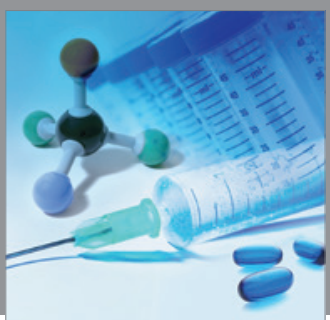

International Journal of

Medicinal Chemistry

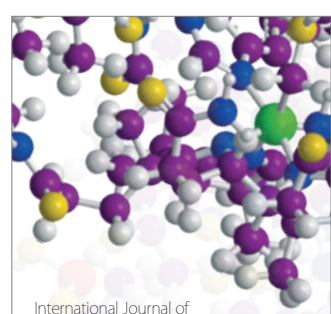

Carbohydrate Chemistry

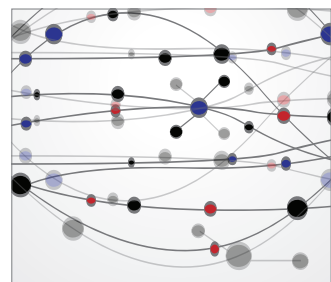

The Scientific World Journal
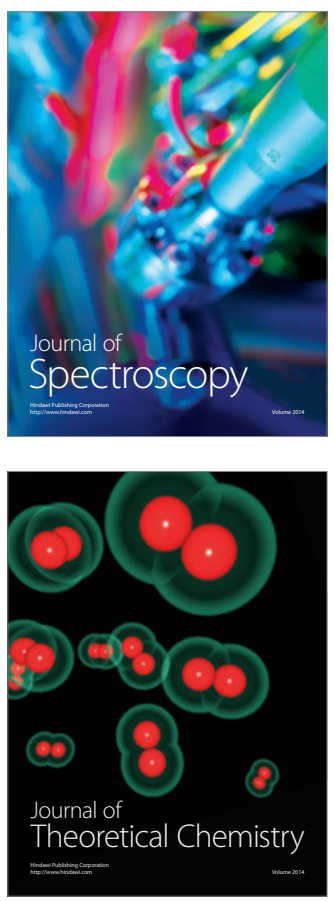
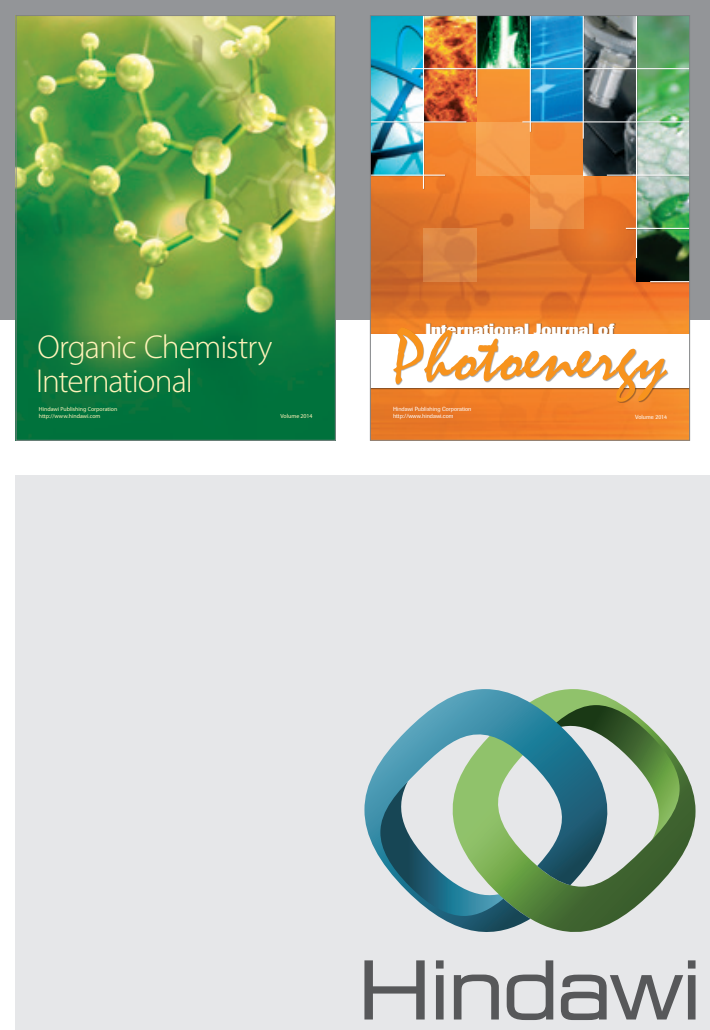

Submit your manuscripts at

http://www.hindawi.com
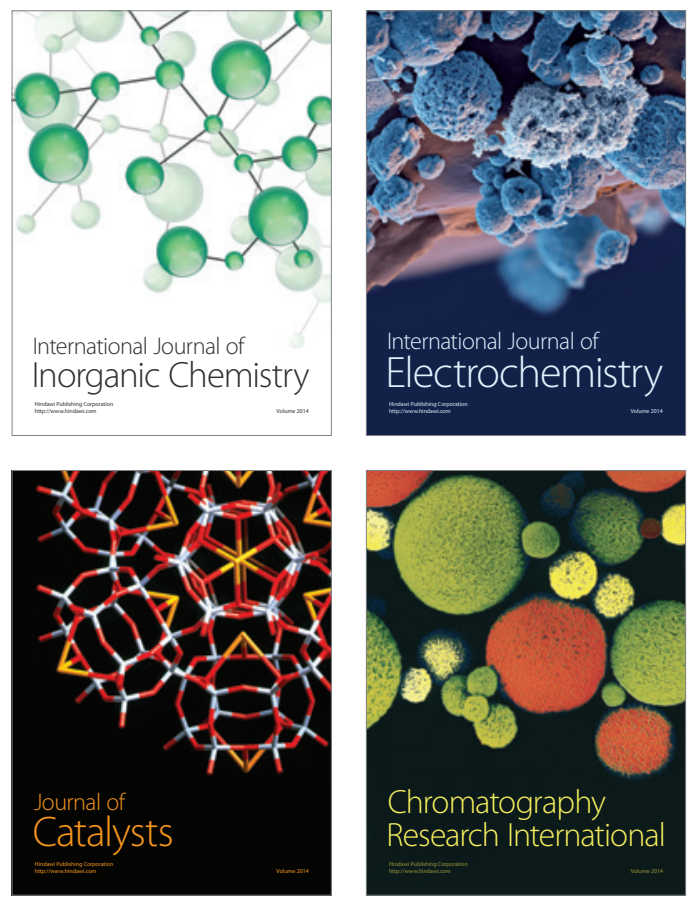
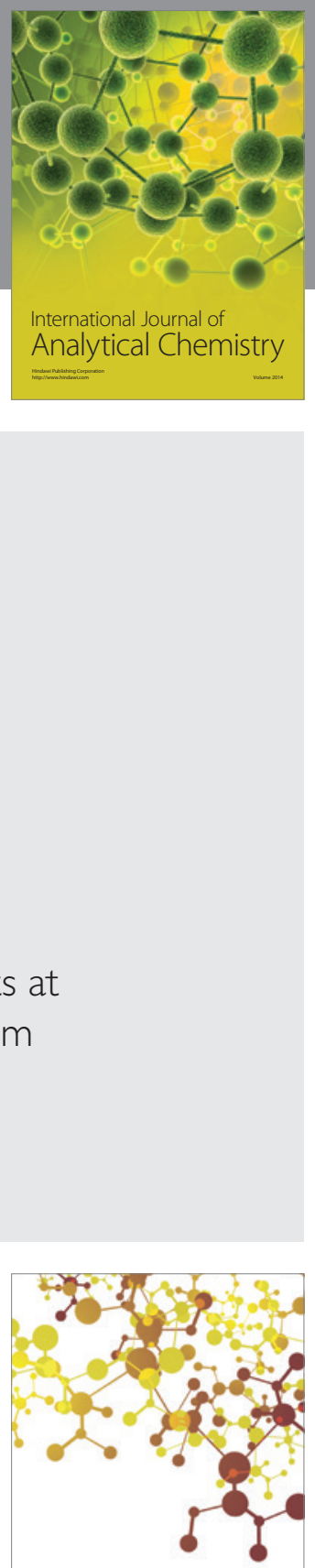

Journal of

Applied Chemistry
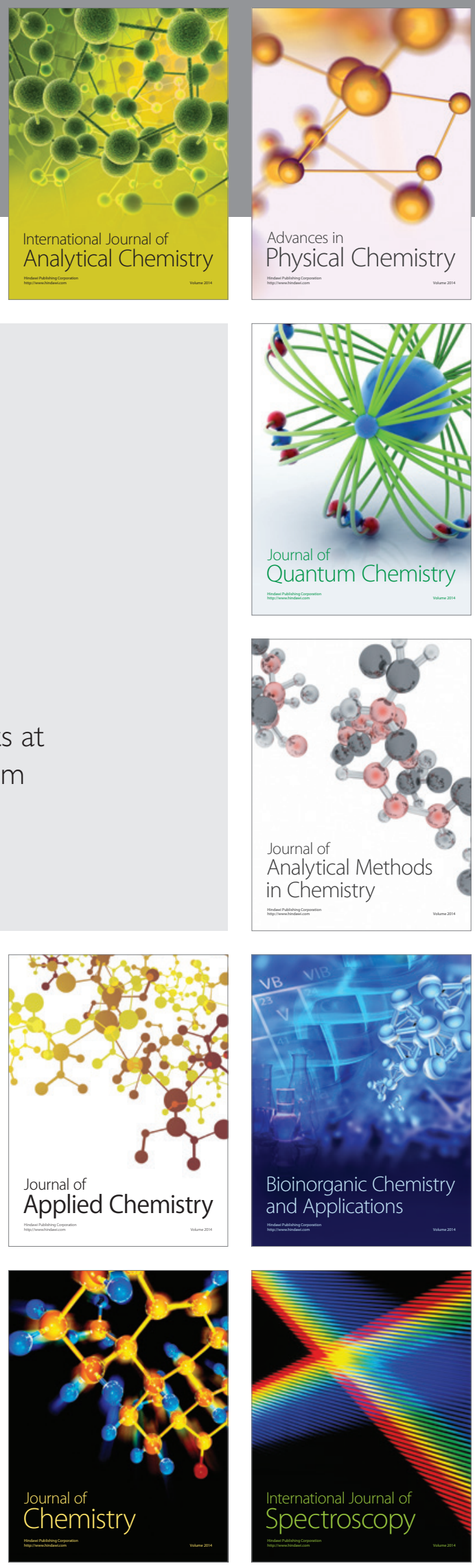